\title{
Application of multivariate statistical methods in the assessment of mountain organic soil transformation in the central Sudetes
}

\author{
Bogna Zawieja ${ }^{1}$, Bartłomiej Glina ${ }^{2}$ \\ ${ }^{1}$ Department of Mathematical and Statistical Methods, Poznań University of Life Science, Wojska \\ Polskiego 28, 60-637 Poznań, Poland; e-mail: bogna13@up.poznan.pl \\ ${ }^{2}$ Department of Soil Science and Land Protection, Poznań University of Life Sciences, Poznań, \\ Poland
}

\section{SUMMARY}

\begin{abstract}
In studies of organic soil degradation and transformation, alongside the conventional methods used in soil science, an increase in the importance of advanced statistical methods can be observed. In this study some multivariate statistical methods were applied in an investigation of organic soil transformation in the central Sudetes. Andrews curves, linear and kernel discriminant variable analysis and cluster analysis were used. The similarities among peatland soils and their layers were determined. It can be stated that the application of statistical methods in soil science research related to organic soil transformation is a valuable tool. The use of various statistical methods (such as Andrews curves, linear and kernel discriminant variables and cluster analysis) can with high probability confirm earlier laboratory or field observations. This is particularly justified in the case of organic soils derived from varied geobotanical peat materials, different types of peatlands and water supply types, which impact the primary properties of the soil.
\end{abstract}

Key words: Andrews curves, degradation, kernel discriminant analysis, linear discriminant analysis, mountain peatlands

\section{Introduction}

Environmental conditions, and hydrological conditions in particular, play an essential role in the functioning of peatlands (Strack et al. 2008). In most cases, disturbances in the water conditions of peatlands are the result of human impact (Limpens et al. 2008; Glina et al. 2016a). Peatland ecosystems, especially during the last century, have been strongly affected by human activity (Heller and Zeit 2012). Evidence of anthropogenic transformations of peatlands is well preserved 
in mountainous areas of Poland, including the Sudetes (Glina et al. 2017; Glina et al. 2016b) and the Carpathians (Lajczak 2013). At the turn of the $19^{\text {th }}$ and $20^{\text {th }}$ centuries mire areas in the central Sudetes underwent intensive drainage treatment (Glina et al. 2017). Drainage connected with forest management causes multidirectional changes in the physical and chemical properties of organic soils (Glina et al. 2016b). In studies of organic soil degradation, alongside the conventional methods used in soil science, an increase in the importance of advanced statistical methods can be observed (Douaik et al. 2011). The precise selection and execution of statistical analyses are significant tools which can confirm the findings arising from field and laboratory observations. Moreover, they enable clear identification of statistically significant differences between the studied objects. In the case of multivariate assessment of peatland transformation, multivariate statistical methods, both visual and metric, may be used. The aim of this study was to assess the correctness of application of various multivariate statistical methods in soil science research concerning organic soil transformation in the central Sudetes. Andrews curves, linear and kernel discriminant variables and cluster analysis were used.

\section{Material and Methods}

The data (Table 1) used in this paper were earlier reported by Glina et al. (2016b). The authors investigated five degraded shallow peatlands located in the Stołowe Mountains (central Sudetes). The studied peatlands were differentiated in terms of ecological type, elevation, type of water supply and mineral bedrock. The study sites represent the following types of peatlands: A and B - peat bogs, C transitional bog, D and $\mathrm{E}$ - fen peatlands. The investigated organic soils were classified as Dystric Ombric Drainic Fibric Hemic Histosols and Eutric Rheic Murshic Sapric Histosols (Lignic) according to FAO-WRB (IUSS Working Group WRB 2015). The representative soil samples for laboratory analysis were sampled from the central part of each study site by genetic soil horizons in three replications (five soil profiles). In the sampled soil material the following 
parameters were determined: degree of peat decomposition, state of secondary transformation $-\mathrm{W}_{1}$ index, mineralization rate $(\mathrm{TOC} / \mathrm{TN})$ expressed as the ratio of total organic carbon to total nitrogen content, content of cold water extractable carbon (CWC) and hot water extractable carbon (HWC), and humification index of organic matter $\left(\mathrm{Q}_{4} / \mathrm{Q}_{6}\right)$. These parameters will hereinafter be referred to as traits. In the first part of the analysis, apart from the above-mentioned chemical properties, the physical properties (MED test - soil hydrophobicity, RF - rubbed fiber content, BD - bulk density, ash - content of mineral material) and depth are also considered (Glina et al. 2016b).

Table 1. Selected properties of organic soils (mean values) - data after Glina et al. 2016b

\begin{tabular}{|c|c|c|c|c|c|c|c|c|}
\hline $\begin{array}{c}\text { Soil } \\
\text { profile }\end{array}$ & $\begin{array}{c}\text { Soil } \\
\text { horizon }\end{array}$ & $\begin{array}{c}\text { Symbol } \\
\text { used in text }\end{array}$ & $\begin{array}{c}\text { Depth } \\
\text { (cm) }\end{array}$ & $\begin{array}{r}\text { CWC } \\
\mathrm{g} \mathrm{k} \mathrm{k}\end{array}$ & $\underset{\mathrm{g}^{-1}}{\mathrm{HWC}}$ & TOC/TN & $\mathrm{Q}_{4} / \mathrm{Q}_{6}$ & $\mathrm{~W}_{1}$ \\
\hline \multirow{5}{*}{ A } & Hi1 & A1 & $0-10$ & 0.62 & 4.69 & 39.1 & 10.6 & 0.39 \\
\hline & $\mathrm{He}$ & $\mathrm{A} 2$ & $10-19$ & 0.40 & 2.51 & 29.3 & 9.08 & 0.33 \\
\hline & $\mathrm{Hi} 2$ & A3 & $19-34$ & 0.34 & 2.14 & 34.3 & 7,58 & 0.27 \\
\hline & $\mathrm{Ha}$ & A4 & $34-37$ & 0.38 & 2.41 & 30.7 & 6.05 & 0.35 \\
\hline & $\mathrm{Hi} 3$ & A5 & $37-54$ & 0.31 & 1.98 & 33.1 & 7,68 & 0.30 \\
\hline \multirow{5}{*}{ B } & Hil & B1 & $0-9$ & 0.67 & 2.90 & 32.9 & 4.81 & 0.52 \\
\hline & $\mathrm{Ha} 1$ & B2 & $9-18$ & 0.23 & 1.02 & 26.5 & 4.48 & 0.55 \\
\hline & $\mathrm{Hi} 2$ & B3 & $18-33$ & 0.32 & 1.66 & 40.5 & 4.20 & 0.30 \\
\hline & $\mathrm{Hi} 3$ & B4 & $33-40$ & 0.27 & 1.61 & 37.2 & 4.67 & 0.35 \\
\hline & $\mathrm{Ha} 2$ & B5 & $40-47$ & 0.18 & 0.91 & 26.8 & 4.40 & 0.72 \\
\hline \multirow{4}{*}{$\mathrm{C}$} & Ha1 & $\mathrm{C} 1$ & $0-8$ & 0.32 & 1.91 & 31.1 & 7.66 & 0.59 \\
\hline & $\mathrm{Ha} 2$ & $\mathrm{C} 2$ & $8-14$ & 0.45 & 2.58 & 25.5 & 7.57 & 0.35 \\
\hline & $\mathrm{Ha} 3$ & C3 & $14-23$ & 0.27 & 1.35 & 27.9 & 7.74 & 0.29 \\
\hline & $\mathrm{Ha} 4$ & $\mathrm{C} 4$ & $23-42$ & 0.19 & 0.94 & 19.2 & 5.76 & 0.35 \\
\hline \multirow{5}{*}{$\mathrm{D}$} & M1 & D1 & $0-12$ & 0.65 & 3.42 & 14.6 & 3.13 & 0.52 \\
\hline & M2 & D2 & $12-20$ & 0.43 & 1.39 & 14.8 & 3.53 & 0.51 \\
\hline & Ha1 & D3 & $20-35$ & 0.23 & 0.83 & 14.8 & 3.52 & 0.42 \\
\hline & $\mathrm{Ha} 2$ & D4 & $35-50$ & 0.27 & 1.05 & 17.4 & 4.09 & 0.41 \\
\hline & Ha3 & D5 & $50-80$ & 0.26 & 1.02 & 21.4 & 3.10 & 0.49 \\
\hline \multirow{4}{*}{ E } & Hal & E1 & $0-20$ & 0.36 & 2.50 & 23.3 & 8.28 & 0.61 \\
\hline & $\mathrm{Ha} 2$ & E2 & $20-30$ & 0.21 & 0.98 & 21.5 & 6,69 & 0.52 \\
\hline & Ha3 & E3 & $30-41$ & 0.09 & 0.82 & 20.2 & 6.52 & 0.54 \\
\hline & $\mathrm{Ha} 4$ & $\mathrm{E} 4$ & $41-49$ & 0.04 & 0.50 & 20.5 & 5.98 & 0.53 \\
\hline
\end{tabular}

Legend: TOC/TN - mineralization rate, $\mathrm{HWC}$ - hot water extractable carbon, $\mathrm{CWC}$ - cold water extractable carbon, $\mathrm{Q}_{4} / \mathrm{Q}_{6}$ - humification index, $\mathrm{W}_{1}-$ state of secondary transformation 
Modified Andrews curves (Khattree and Naik 2002; Anderson 2003) were used to present each multivariate variable $X_{r i}=\left(X_{r i, 1}, \ldots, X_{r i, p}\right)$, where $r=1, \ldots, c$ represents the $r^{\text {th }}$ peatland, $i$ is the observation taken in the $r^{\text {th }}$ peatland ( $\left.i=1, \ldots, n_{r} ; \sum_{r=1}^{c} n_{r}=n\right)$, and $p$ is the number of traits. These variables were transformed to a curve as follows:

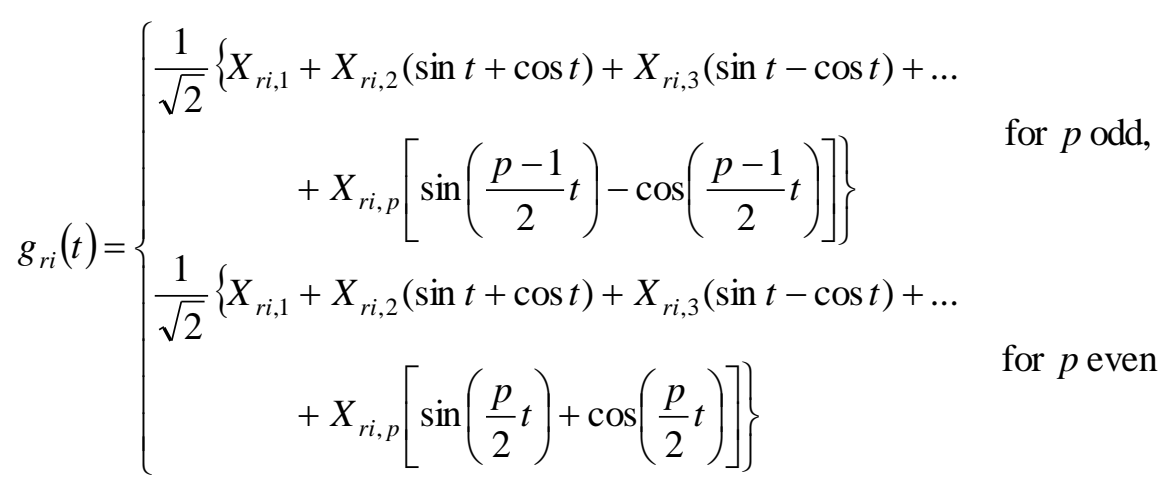

observations represent the coefficients of Fourier's series for $t \in[-\pi, \pi]$. Outliers appear as single Andrews curves that look different from the rest. In this study $X_{r i}=\left(X_{r i, 1}, \ldots, X_{r i, p}\right)$ is represented by the curve:

$$
\begin{aligned}
g_{r i}(t)= & \frac{1}{\sqrt{2}}\left[X_{r i, 1}+X_{r i, 2}(\sin t+\cos t)+X_{r i, 3}(\sin t-\cos t)+X_{r i, 4}(\sin 2 t+\cos 2 t)+\right. \\
& +X_{r i, 5}(\sin 2 t-\cos 2 t)+X_{r i, 6}(\sin 3 t+\cos 3 t)+X_{r i, 7}(\sin 3 t-\cos 3 t)+ \\
& \left.X_{r i, 8}(\sin 4 t+\cos 4 t)+X_{r i, 9}(\sin 4 t-\cos 4 t)+X_{r i, 10}(\sin 5 t+\cos 5 t)\right]
\end{aligned}
$$

The curves $g_{r i}(t)\left(r=1, \ldots, c, i=1, \ldots, n_{r}\right)$ are presented on a plane. Similarity among the shapes of curves suggests similarity among observations. In determining the Andrews curves the division of observations into groups was not used, but because the order of variables has a huge impact on the shape of curves (provided that the sequence of variables is not determined), variables should be sorted in decreasing order.

The linear discriminant variables method is used to detect differences between multidimensional observations using the within-group covariance matrix (Krzyśko 2009; Zawieja and Kaźmierczak 2016). In this method the knowledge of a given observation's belonging to the group was used. The 
maximum of the class differentiation index $J\left(\mathbf{a}_{l}\right)=\left(\mathbf{a}_{l}{ }^{\prime} \mathbf{S}_{\mathbf{B}} \mathbf{a}_{l}\right) /\left(\mathbf{a}_{l}{ }^{\prime} \mathbf{S}_{\mathbf{w}} \mathbf{a}_{l}\right)$ is searched under the condition $\mathbf{a}_{l}{ }^{\prime} \mathbf{S}_{\mathbf{w}} \mathbf{a}_{k}=\delta_{l k}$ (Kronecker delta), where $\mathbf{S}_{\mathbf{B}}$ is the estimator of the known interclass variation matrix, $\mathbf{S}_{\mathbf{w}}$ is the estimator of the known within-class variation matrix, $\mathbf{a}_{l}$ is the searched vector of coefficients, $l, k=1,2, \ldots, s$ and $s \leq \min (p, r-1)$. The $l^{l h}$ discriminant variable takes the form $\mathbf{u}_{l}=\mathbf{a}_{l}{ }^{\prime} \mathbf{X}$. The number of discriminant variables $s$ depends on the significance of the discriminant variables $\mathbf{u}_{l}$.

Nonlinear kernel discriminant variable analysis allows another look at the data using the curvature of the space (Deręgowski and Krzyśko 2014; Zawieja and Kaźmierczak 2016) to linearly separate the data. In this case finding discriminatory variables in the trait space is reduced to solving the optimization problem $\mathbf{b}_{o}=\arg \max \left[\left(\mathbf{b}_{l}{ }^{\prime} \mathbf{K D K} \mathbf{b}_{l}\right) /\left(\mathbf{b}_{l}{ }^{\prime} \mathbf{K K} \mathbf{b}_{l}\right)\right]$, where the elements of the matrix $\mathbf{D}$ are $1 / n_{r}$ if $\mathbf{x}_{r i}$ and $\mathbf{x}_{r i r}$ belong to the same class $\left(r=r^{\prime}\right)$ and zero otherwise, $\mathbf{K}=\mathbf{P} \tilde{\mathbf{K}} \mathbf{P}$ with $\mathbf{P}=\mathbf{I}_{n}-\frac{1}{n} \mathbf{1}_{n} \mathbf{1}_{n}^{\prime}$ (matrix of centering) and $\tilde{\mathbf{K}}=\left(k_{i i^{\prime}}\right)$ with $k_{i i}=k\left(\mathbf{x}_{r i}, \mathbf{x}_{r i i^{\prime}}\right)$ is the kernel matrix, and $\mathbf{b}_{l}$ is the searched vector of coefficients. The $l^{\text {th }}$ kernel discriminant variable is in the form $\mathbf{v}_{l}=\mathbf{b}_{l}{ }^{\prime} \mathbf{K}$. The Gaussian kernel function $k(\mathbf{x}, \mathbf{y})=\exp \left(-\|\mathbf{x}-\mathbf{y}\|^{2} / \sigma\right)$ is used for calculation of nonlinear discriminant variables with $\sigma=\sum\|\mathbf{x}-\mathbf{y}\|^{2}$.

Cluster analysis is applied, using variables from discriminant and kernel discriminant analyses (the Ward method with Euclidian distance is applied) to distinguish groups.

In this paper a comparison of peatlands was performed both (I) for all variables (physical and chemical properties jointly) and (II) for traits determining the degree of conversion of peatlands (index $\mathrm{W}_{1}, \mathrm{CWC}, \mathrm{HWC}, \mathrm{TOC} / \mathrm{TN}$ and $\left.\mathrm{Q}_{4} / \mathrm{Q}_{6}\right)$, in the following way:

- Evaluation of organic soil degradation, based on Andrews curves.

- Determination of linear discriminant variables and presentation of data in the plane of the first and second discriminant variables and in the plane of the first and third discriminant variables.

- Cluster analysis for transformed, by discriminant analysis, variables whose number is dependent on the significance of their contribution to the model. 
- Determination of kernel discriminant variables and presentation of data in the plane of the first and second discriminant variables.

- Cluster analysis for transformation of data by kernel discriminant analysis.

\section{Results}

I (1) Chemical and physical properties jointly. The Andrews curves (Figure 1a) of study soil A have similar function graphs (one bundle of curves). The curves of organic soil D are also quite similar, but there is a greater diversity among the studied soil horizons (the amplitudes of the individual curves differ quite considerably). In the case of soil profiles B, C and E, Andrews curves do not form separate bundles, but are mixed, and the soil horizons vary only in terms of amplitude. The deepest soil layers of profiles $\mathrm{C}$ and $\mathrm{D}$ are clearly distinguishable from the other investigated soils (Figure 1d, e). In soil profile B (Figure 1c) great differences between surface horizons B1 and B2 were observed, the result of different degrees of peat decomposition (fibric-sapric) and mineralization rate. The greatest amplitudes are observed in the case of soil horizon B2 (high values of parameters). The individual horizons of peat soils B, C and E (Figure 1c,d,f) were quite diverse as regards amplitude. The lines of horizons E1 and $\mathrm{C} 2$ are similar to lines D1-D3 of profile D (fen peatland). Moreover, similarities were observed between curves E1 and C2 and between E3 and B5. The vast majority of deeper soil horizons were characterized by large amplitude relative to the surface horizons.

I (2) Chemical properties (because CWC and HWC are strongly correlated, with a correlation coefficient of $89 \%$, only one of these traits - CWC - is used). In this study the impact of all traits on the differentiation of peatland soils is of interest. Thus the first step of linear discriminant analysis, concerning the number of traits having an impact on the division of observations, is omitted, and all traits are used in the analysis. In the next step of this analysis the number of discriminant variables having a significant impact on the grouping of observations is determined. The $p$-values for the discriminant variables are as follows: for $\mathbf{u}_{1}$ 
and $\mathbf{u}_{2}: p<0.0001$, for $\mathbf{u}_{3}: p=0.0031$; for $\mathbf{u}_{4}: p=0.1486$; for all other variables the $p$ value is greater than 0.05 , thus only the first three variables are used in the analysis. The traits $\mathrm{CWC}$ and $\mathrm{HWC}$ have the greatest contribution to the first two discriminant variables. In the results (Figure 2a,b) each of the organic soils (A, B, C, D and E) can be linearly separated. In the plane of the first two discriminant variables, profiles $\mathrm{A}$ (peat bog) and $\mathrm{C}$ (transitional bog) are very close. However, the third variable completely separates these soils.

I (3) Cluster analysis (Figure 2c) was performed based on the first three discriminant variables. As a result of this analysis the structure of the studied organic soils is obtained. The soil horizons within profiles A and D are alternated. A similar arrangement is shown by the Andrews curves. In soil B the genetic horizons 2 and 3 are similar to 5 in respect of the examined traits. In profile $C$ (transitional bog) two of the deeper soil layers are the most similar (on the basis of Andrews curves layer 4 is separated). Moreover the soil layer E1 is connected with horizons within organic soil C.

I (4) The use of kernel discriminatory variables (Figure 3a) with Gaussian kernel shows that the soil horizons in peat bog profiles (site A) and the uppermost layers of the peat bogs $B$ are similar. Furthermore, soil layers $C 1, C 2$ and $C 3$ in profile $\mathrm{C}$ are similar to the horizons B3, D2 and E1. Soil layers D1, D3 and D4 in profile D are similar to each other, and finally the deeper layers C4, B5, B4, D5, E3, E4, as well as E2, are in one group.

I (5) In the cluster analysis diagram (Figure 3b) three or four clusters can be distinguished. The first combines all of the soil horizons within profile A and moorsh horizons D1 and D2 (profile D); the second is mainly composed of soil horizons from transitional bog (site C). Soil horizons B3, D2 and E1 also belong to this cluster. The third cluster exclusively represents organic soils from fen peatland D. These two clusters (the second and third) can be connected. The last cluster combines all soil horizons (except layer E1) from profile E and the deepest layers of organic soils from study sites C, D and B. 

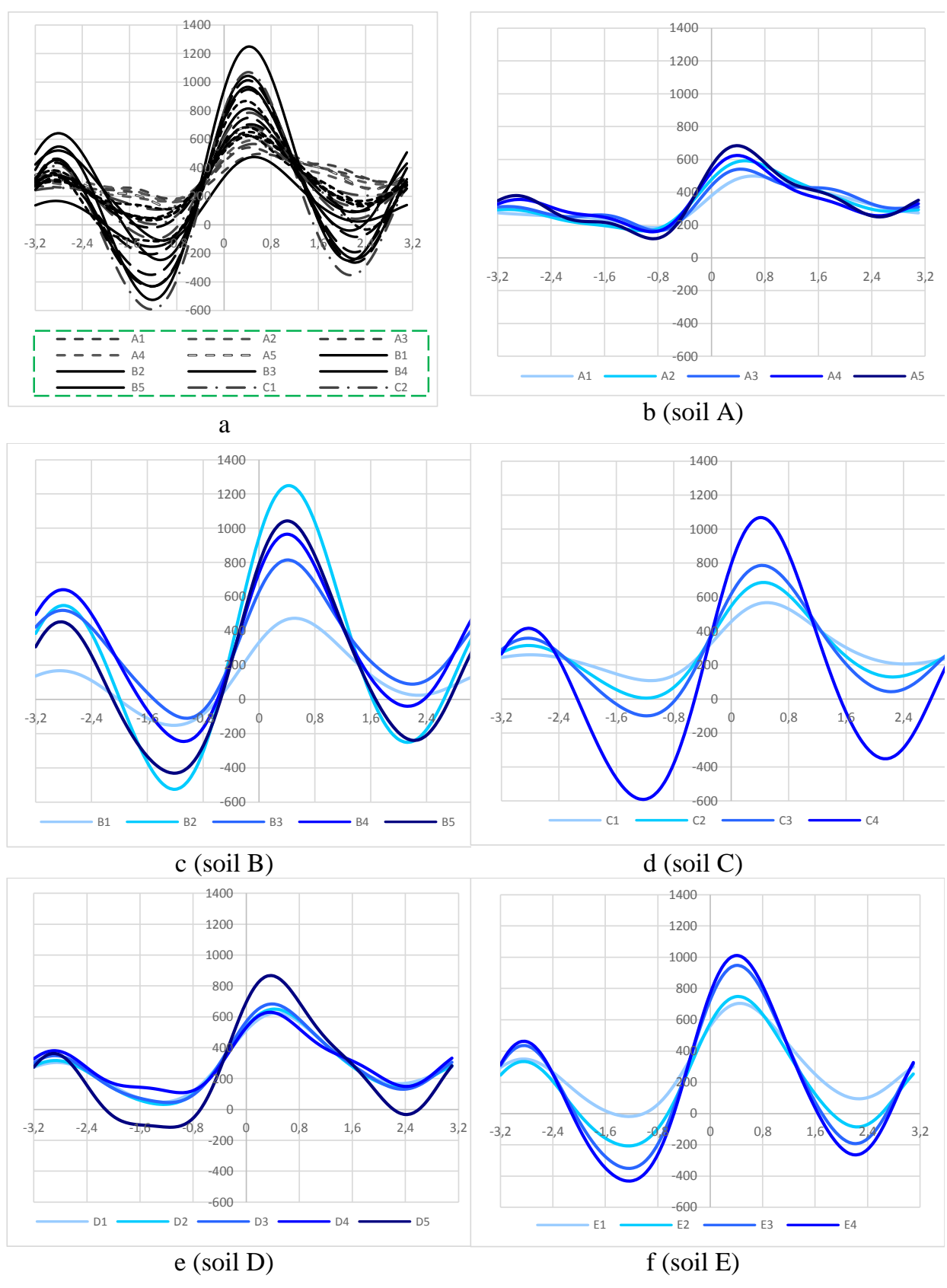

Figure 1. Andrews curves: a - All studied soil horizons; b-f - Soil horizons of separate study soils 


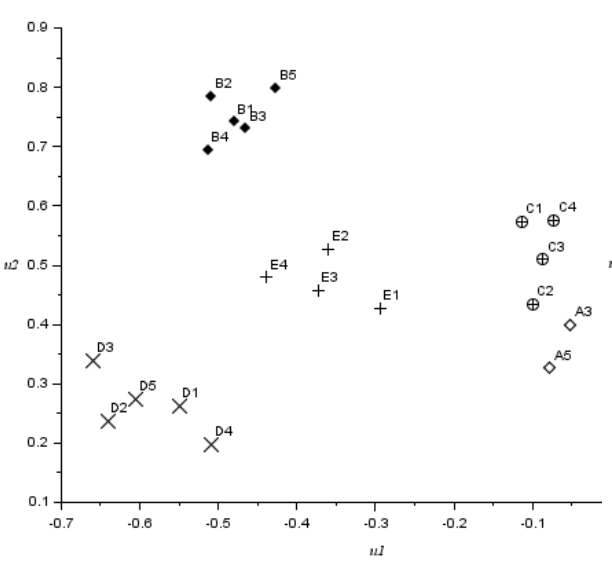

a

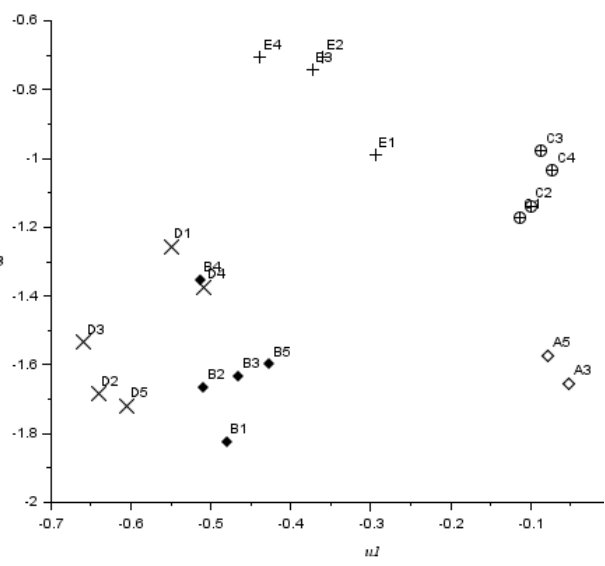

B

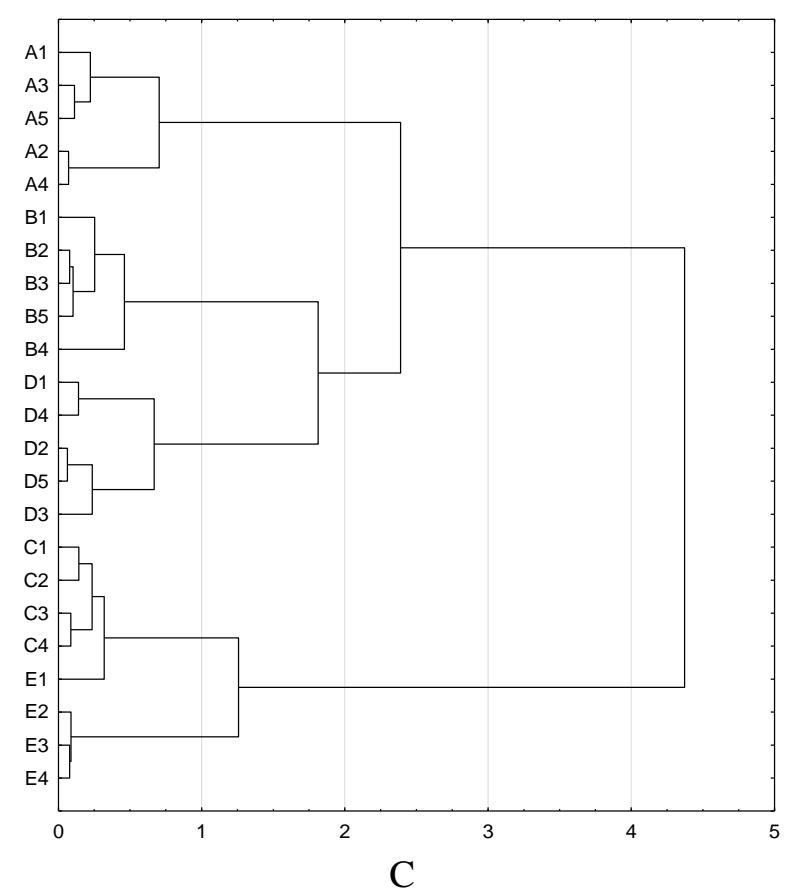

Figure 2. $\mathrm{a}, \mathrm{b}$ - Linear discriminant variables ( $\mathrm{a}$ - first and second, $\mathrm{b}$ - first and third); $\mathrm{c}$ - Tree diagram for the first three linear discriminant variables

II (1) Based on the Andrews curves the lines can be divided into two groups as regards their shape (Figure 4a): namely soil profiles A, C and E are in the first group (large amplitude) and D and B in the second (small amplitude). In the case 
of profiles $\mathrm{A}, \mathrm{B}$ and $\mathrm{C}$ the soil horizons are arranged in alternating order (Figure $4 b, c, d$ ). In Figure 4a (and also c, e, f) it is visible that the lines for soil horizons B1, B5, D1, D2, D3, E3 and E4 are almost identical. For these four traits the surface horizons of the examined soils (except profiles D and A) have the largest amplitude. It is seen that these profiles differ significantly from each other

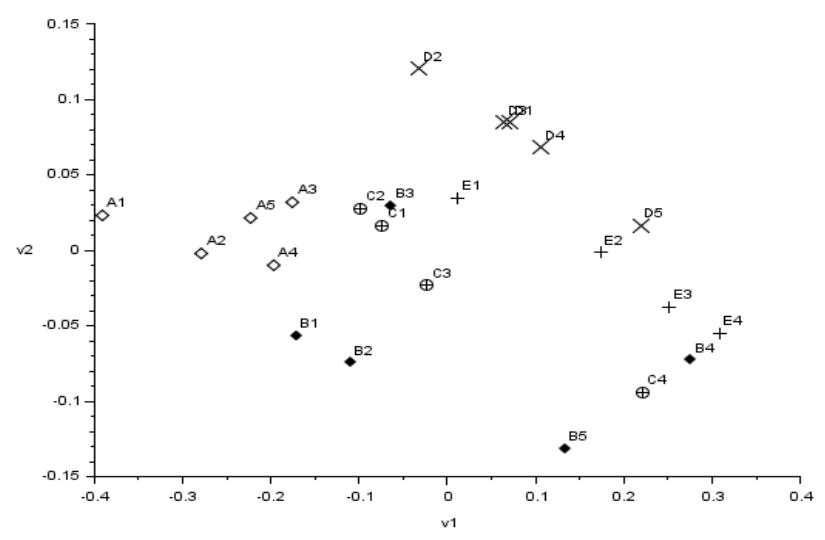

a

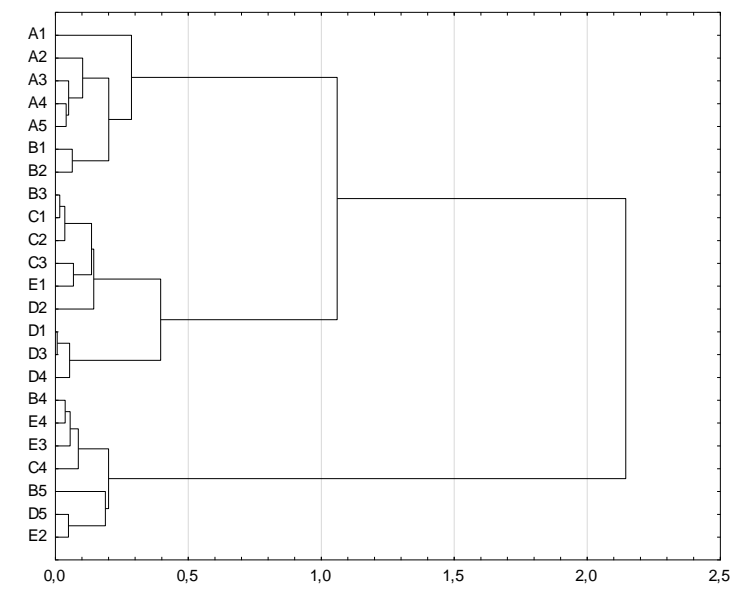

b

Figure 3. $a$ - Kernel discriminant variables with Gaussian kernel; $b$ - Tree diagram for the first two kernel discriminant variables 

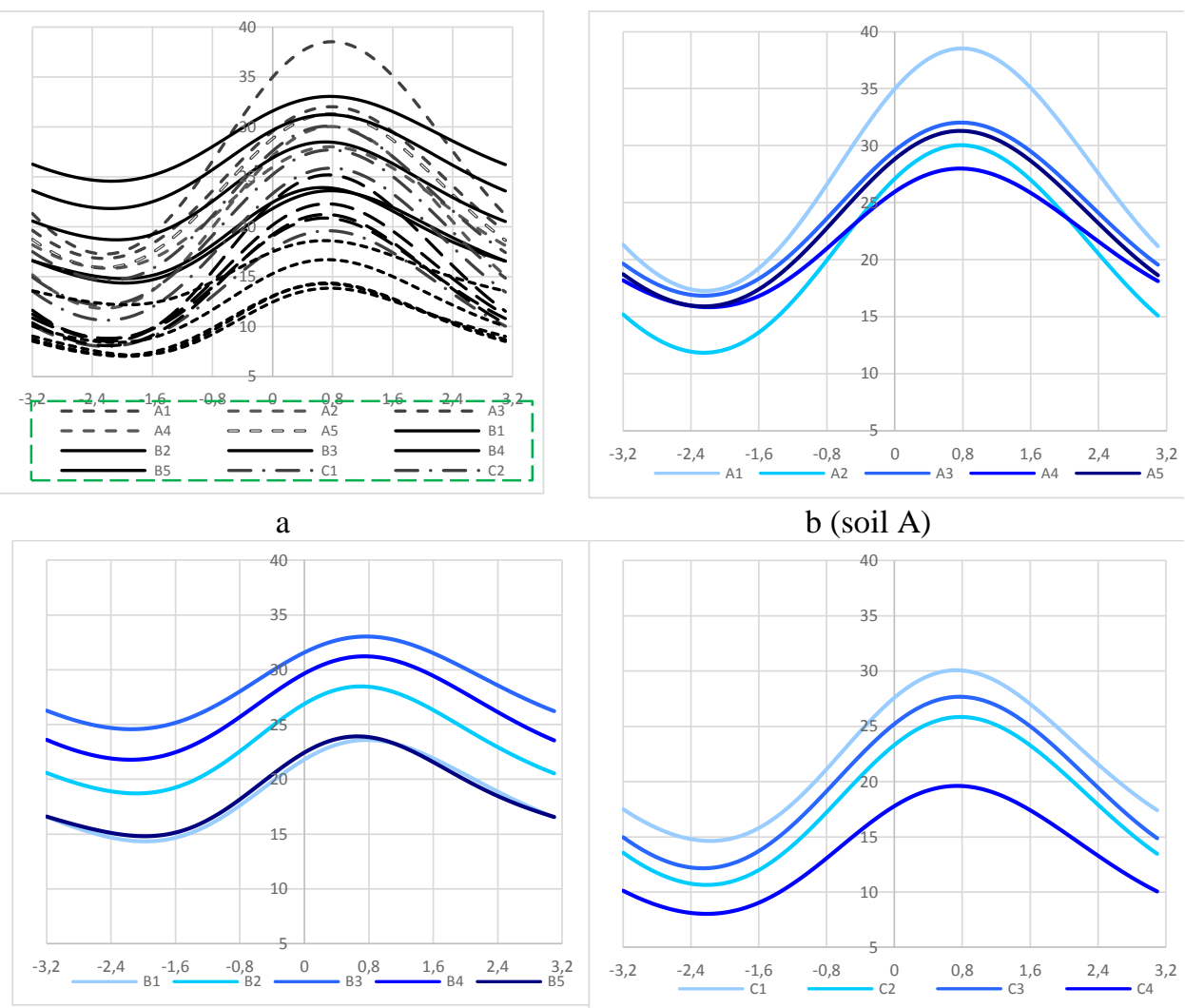

c (soil B)
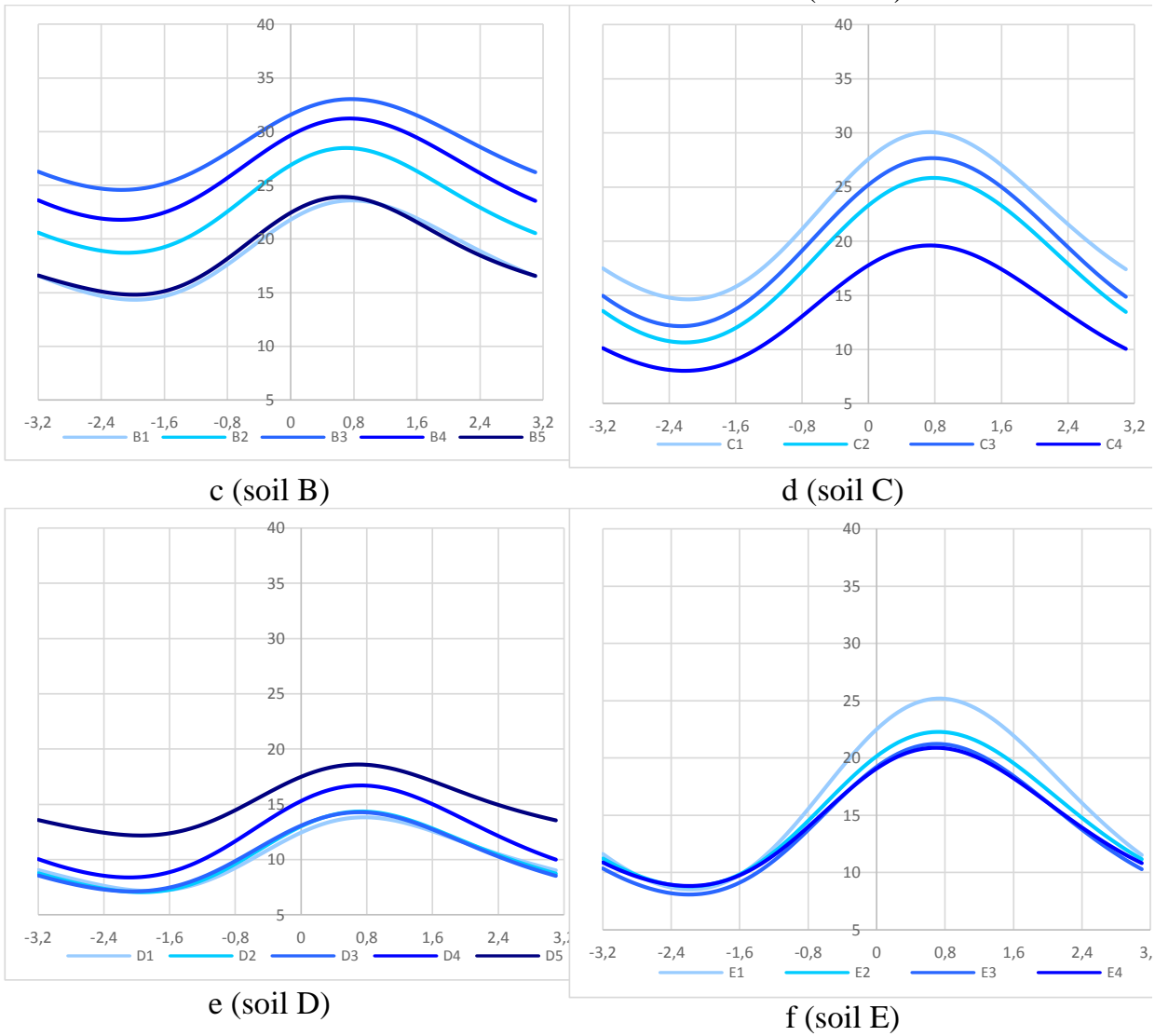

Figure 4. Andrews curves: a - All soil horizons; b-f - Soil horizons of separate study soils 
II (2) Three discriminant variables have a significant impact on the grouping of observations. The $p$-values for the first four variables are as follows: for $\mathbf{u}_{1}$ and $\mathbf{u}_{2}: p<0.0001$, for $\mathbf{u}_{3}: p=0.0287$; for $\mathbf{u}_{4}: p=0.7392$.The traits: TOC/TN and $\mathrm{Q}_{4} / \mathrm{Q}_{6}$ have the greatest contribution to the first two discriminant variables. Soil profiles D (fen peatland) and B (peat bog) can be separated from the group containing A (peat bog), C (transitional bog) and $\mathrm{E}$ (fen peatland) in the plane of the first two discriminant variables (Figure 5a, b). Moreover, profiles D and B can be separated from each other. Additionally, based on the third discriminant variable (in the plane of the first and third discriminant variables) two groups can be separated; the first contains two organic soils A and C, and the second contains peatland E. This analysis almost shows that soil horizons D1 and D2 (moorsh) are separated from the other layers, which results from the different properties of moorsh material.

II (3) The clustering tree diagram (Figure 5c) generally gives a similar division of the study soils. Namely profiles A, C and E are in one cluster, while soils B and $\mathrm{D}$ belong to the second cluster. The more detailed division into clusters is as follows: the soil horizons A1, A2, C1, C2, C3, A3 and A5 represent the first group, soil profiles from peatland $\mathrm{E}$ and the single horizon $\mathrm{C} 4$ constitute the second group, and horizons D1, D2 and A4 are in the third group. The last (fourth) group consists of organic soils from peatland B and soil horizons D3, D4 and D5 from peatland $\mathrm{D}$. These results indicate that soil transformation in peat bog (site B), deeper soil layers in particular, and fen peatland (site D) are generally at the same level.

II (4). Based on the kernel discriminant variables method, three or four groups can be distinguished. All of the investigated soil samples from profile D are allocated to the first group (Figure 6a). The second group consists of layers within organic soil E and certain horizons (B5, B4, C2, C4) from profiles B and C. Soil horizons A1, A2, A3 and C1 make up the third group, and A4, B1, B2 and C3 the last group. Groups three and four can be considered jointly. Among all investigated soil horizons, only A5 from the peat bog profile was separated. 
II (5) Cluster analysis confirms the results obtained by method II (4), but with one exception: soil horizon A5 belongs to the group containing surface layers A1, A2, A3 of soils from peatland A and soil horizon C1 (Figure 6b).

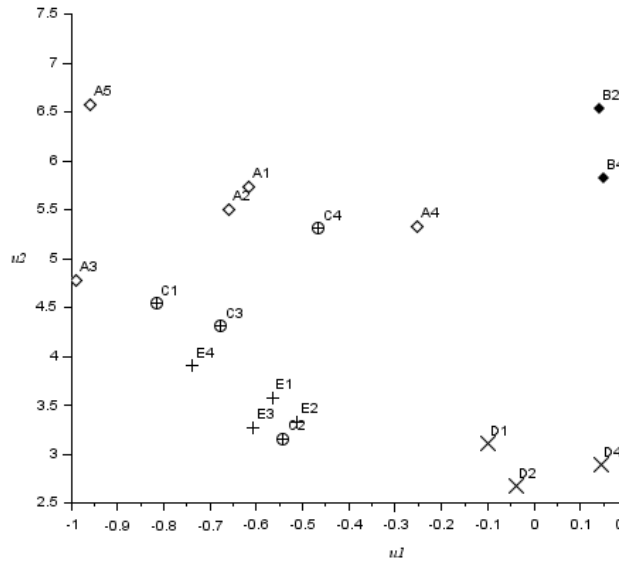

a

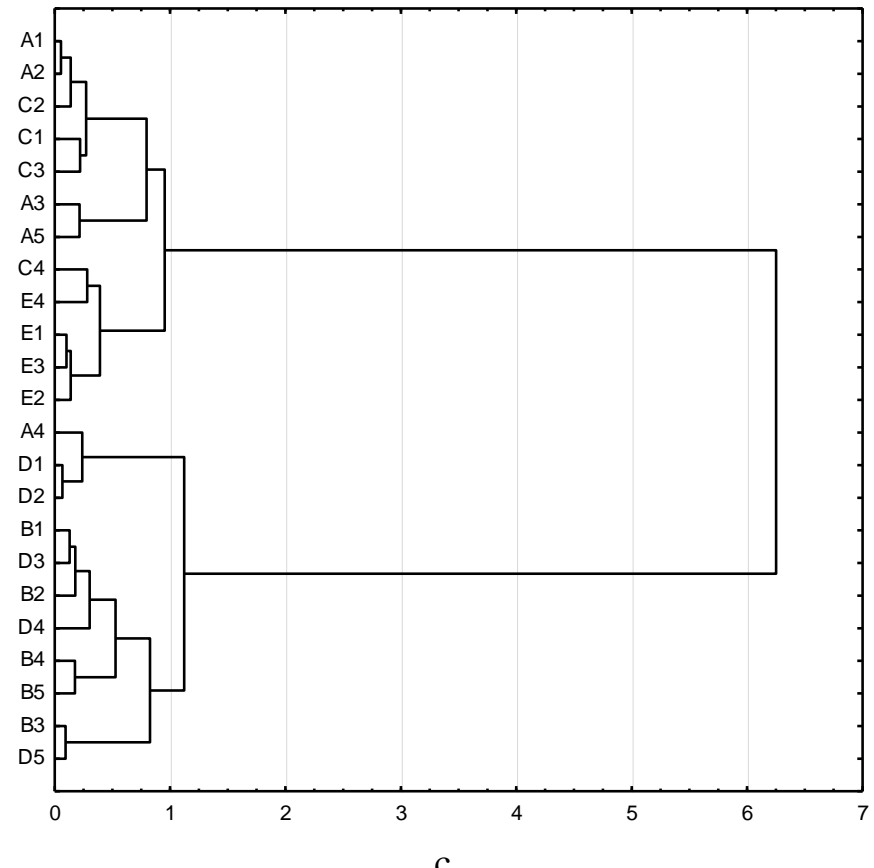

Figure 5. $\mathrm{a}, \mathrm{b}$ - Linear discriminant variables ( $\mathrm{a}$ - first and second, $\mathrm{b}$ - first and third); c - Tree diagram for the first three linear discriminant variables 


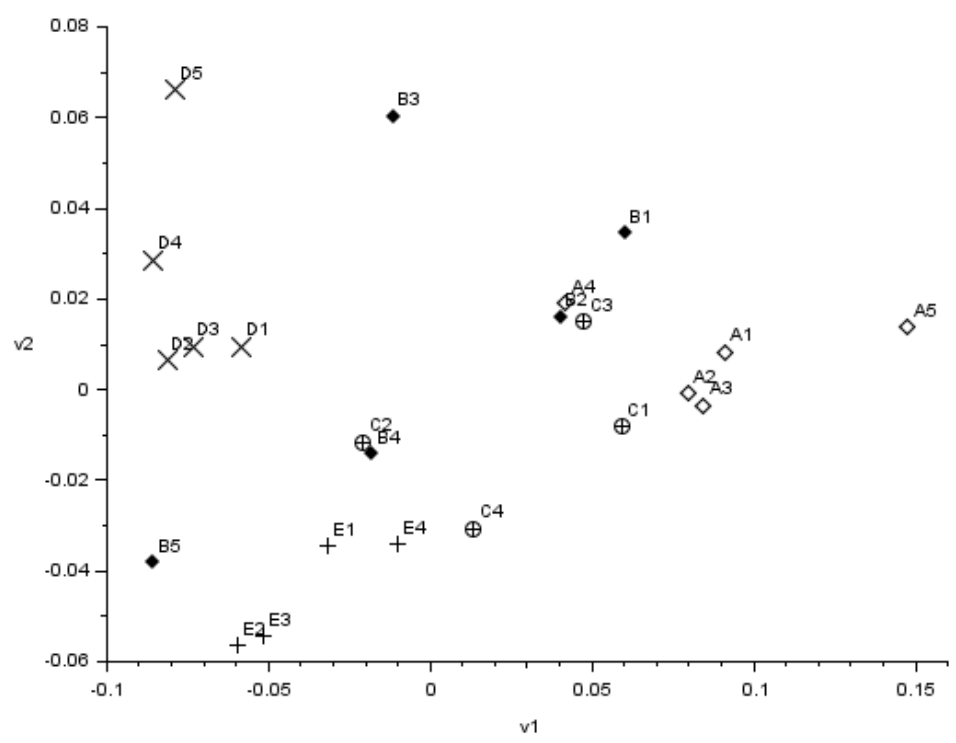

a

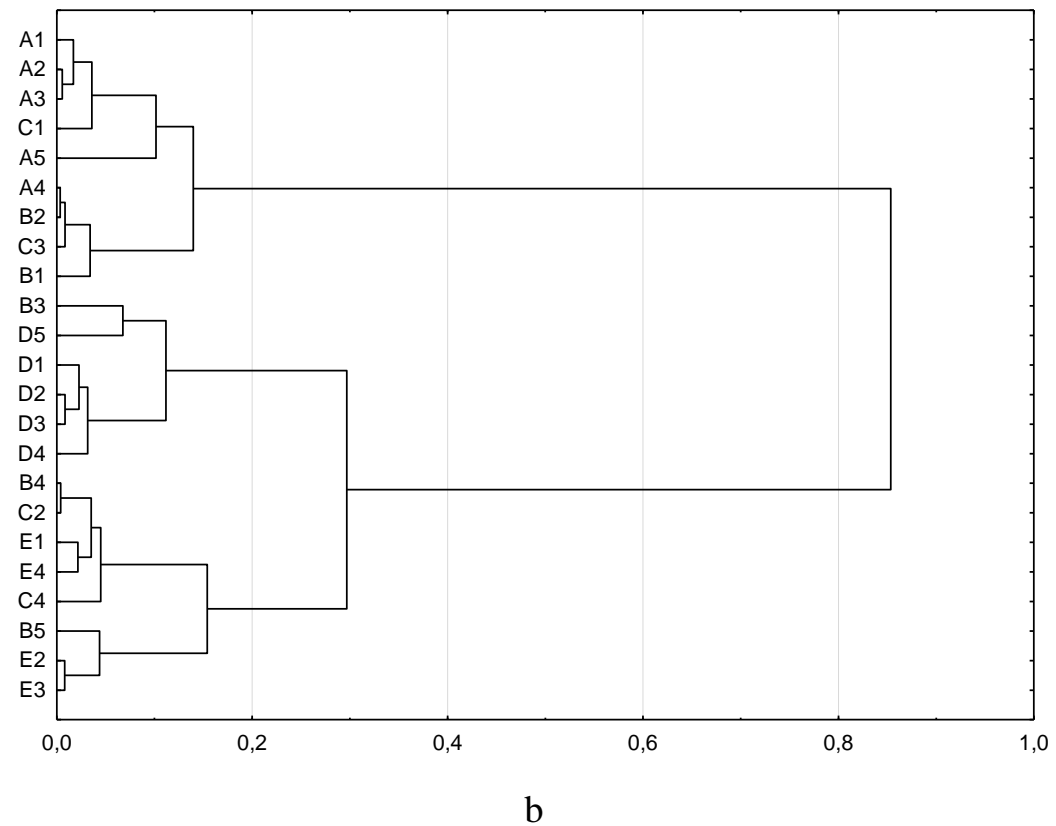

Figure 6. a - Kernel discriminant variables with Gaussian kernel; b - Tree diagram for the first two kernel discriminant variables 


\section{Conclusions}

\section{Analysis of all traits}

Based on the described Andrews curve analysis for individual observations (soil horizons) in organic soil A, it can be stated that the soil layers do not differ in terms of the studied traits. However, they clearly differ from the other studied soils. The soil horizons within profiles B, C, D and E are intermixed in terms of the analyzed traits. Similarly as in the case of A, the soil horizons within profile $\mathrm{D}$ are quite similar, but they are somewhat mixed mainly with the shallow layers of $\mathrm{C}$ and $\mathrm{E}$. These analyses showed the internal structure of organic soils; the studied soil layers were not arranged in order of depth, but in terms of specific traits. Discriminant variables and cluster analysis also make it possible to separate the studied soils; e.g. soil C (transitional bog) is similar to soil E (fen peatland), whereas soil D (fen peatland) is similar to soil B (peat bog). This was also proved by kernel discriminant analysis. Despite the diversity of the parent peat material, statistical analysis is useful in finding similarities between soil properties related to soil transformation.

\section{Analysis of traits determining the degree of organic soil transformation}

The division of soils into two groups is obtained by application of the Andrews curve method and discriminant variables method. The first group contains organic soils A, C and E, and the second contains soils D and B. Moreover, the surface moorsh horizons in soil D were separated in this analysis. These observations are in line with the results of laboratory analysis, which also showed strong differentiation of these layers. In the case of soils A and C, similarities between the surface soil horizons as regards the degree of transformation were also recorded. From Andrews curves it can be concluded that the fen peatland D is the most transformed, and that next in order are fen peatland $\mathrm{E}$, transitional bog C, peat bog A and peat bog B. From discriminant analysis it is concluded that soil A and the surface horizons of B (both peat bog) and soil C (transitional bog) are 
rather weakly transformed. However, the results obtained for horizon B1 are close to those for the moorsh layers in profile D.

Based on the above conclusions it can be stated that the application of statistical methods in soil science research related to organic soil transformation is a valuable tool. The use of various statistical methods (such as Andrews curves, linear and kernel discriminant variables and cluster analysis) can with high probability confirm earlier laboratory or field observations. This is particularly justified in the case of organic soils derived from varied geobotanical peat materials, different types of peatlands and water supply types, which impact the primary properties of soil.

\section{REFERENCES}

Anderson T.W. (2003): An Introduction to Multivariate Statistical Analysis. New York, Wiley.

Baudat G., Anour F. (2000): Generalized discriminant analysis using a kernel approach. Neural Computation 12: 2385-2404.

Deręgowski K., Krzyśko M. (2014): A kernel based learning algorithm combining kernel discriminant coordinates and kernel principal components. Biometrical Letters 51(1): 57-73.

Douaik A., van Meirvenne M., Tóth T. (2011): Statistical Methods for the Analysis of Soil Spatial and Temporal Variability, Principles, Application and Assessment in Soil Science. In. Burcu Özkaraova Güngör (Ed.), InTech, DOI 10.5772/28927.

Glina B., Gajewski P., Kaczmarek Z., Owczarzak W., Rybczyński P. (2016a): Peatland soils degradation as an effect of long-term drainage - preliminary results of peatland ecosystems investigation in the Grójecka Valley (Central Poland). Soil Science Annual 67(1): 1-7. DOI 10.1515/ssa-2016-0001

Glina B., Bogacz A., Gulyas M., Zawieja B., Gajewski P., Kaczmarek Z. (2016b): The effect of long-term forestry drainage on the current state of peatland soils: A case study from the Central Sudetes, SW Poland. Mires\&Peat 18(21): 111. DOI 10. 19189/MaP.2016.OMB.239

Glina B., Malkiewicz M., Mendyk Ł., Bogacz A., Woźniczka P. (2017): Human affected disturbances in vegetation cover and peatland development in the late Holocene recorded in shallow mountain peatlands (Central Sudetes, SW Poland). Boreas. 46(2): 294-307. DOI 10.10.1111/bor.12203

IUSS Working Group WRB (2015): World reference base for soil resources 2014 update 2015. International Soil Classification System for Naming Soil and Creating Legends for Soil Maps. Food and Agriculture Organization of the United Nations, Rome, 190. 
Jing Z., Weiqing M., Ye Z. (2015): Fisher linear discriminant method for forest fire risk points on transmission line. International Journal of Smart Home. 9(4): 25-34. DOI 10.14257/ijsh.2015.9.4.03

Khattree, R., Naik D.N. (2002): Association in contingency tables, correspondence analysis and (modified) Andrews plots. In: Huber-Carol, C., N. Balakrishnan, M.S. Nikulin, M. Mesbah (Eds.). Goodness-of-fit Tests and Model Validity. Birkhäuser, Boston: 311-326.

Krzyśko M. (2009): Fundamentals of multivariate statistical inference (in Polish). Wydawnictwo Naukowe UAM, Poznań: 267-278.

Łajczak A. (2013): Role of land relief and structure in the formation of peat bogs in mountain areas, as exemplified by the Polish Carpathians. Landform Analysis 22: 61-73.

Limpens J., Berendse F., Blodau C., Canadell J.G., Freeman C., Holden J., Roulet N., Rydin H., Schapeman-Strub G. (2008). Peatlands and the carbon cycle: from local processes to global implications - a synthesis. Biogeosciences, 5: 1379-1419.

Mika S., Rätsch G., Weston J., Schölkopf B., Müller K.R. (1999): Fisher discriminant analysis with kernels. In: Neural Networks for Signal Processing (Hu Y.H, Larsen J., Wilson E., and Douglas S. Eds.) IX: 41-48.

Strack M., Waddington J.M., Bourbonniere R.A., Buckton E.L., Shaw K., Whittington P., Price J.S. (2008): Effect of water table drawdown on peatland dissolved organic carbon export and dynamics. Journal of Hydrological Processes 22: 3373-3385.

Zawieja B., Kaźmierczak K. (2016): Oaks allocation to Kraft classes based on linear and nonlinear kernel discriminant variables. Biometrical Letters, 53(1): 37-46. DOI 10.1515/bile-2016-0005 